\title{
CPV generator with dish reflector and fly's eye receiver
}

Cite as: AIP Conference Proceedings 2012, 030008 (2018); https://doi.org/10.1063/1.5053507 Published Online: 13 September 2018

Justin Hyatt, Christian Davila, Nicholas Didato, Rodolfo Peon, Matt Rademacher, Dima Reshidko, Frank Sodari, Peter Strittmatter, Galen Vincent, Brian Wheelwright, Corey Zammit, and Roger Angel

\section{ARTICLES YOU MAY BE INTERESTED IN}

REhnu dish based CPV: Performance and reliability improvements based on a year of field experience

AIP Conference Proceedings 2012, 020004 (2018); https://doi.org/10.1063/1.5053492

Improvements in the manufacturing process of achromatic doublet on glass (ADG) Fresnel lens

AIP Conference Proceedings 2012, 030009 (2018); https://doi.org/10.1063/1.5053508

On-sun testing of a 100-shingled-cell dense receiver array at $\sim 50 \mathrm{~W} / \mathrm{cm}^{2}$ using overlapped single-axis foci

AIP Conference Proceedings 2012, 020009 (2018); https://doi.org/10.1063/1.5053497

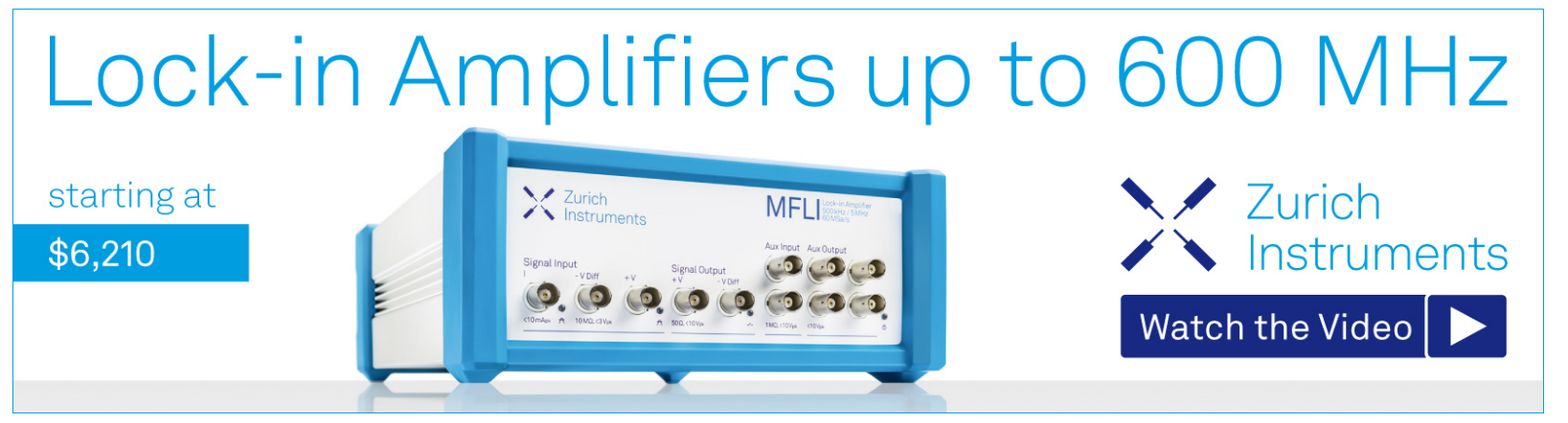




\title{
CPV Generator with Dish Reflector and Fly's Eye Receiver
}

\author{
Justin Hyatt ${ }^{1,2, a)}$, Christian Davila ${ }^{1}$, Nicholas Didato ${ }^{1,3}$, Rodolfo Peon ${ }^{1}$, Matt \\ Rademacher $^{1}$, Dima Reshidko ${ }^{2}$, Frank Sodari ${ }^{1,3}$, Peter Strittmatter ${ }^{1,3}$, Galen \\ Vincent $^{1}$, Brian Wheelwright ${ }^{2}$, Corey Zammit ${ }^{1}$ and Roger Angel ${ }^{1,2,3}$ \\ ${ }^{1}$ Steward Observatory, University of Arizona, justinjh@email.arizona.edu, Tucson, Az, USA \\ ${ }^{2}$ College of Optical Sciences, University of Arizona, Tucson, Az, USA \\ ${ }^{3}$ REhnu Inc., Tucson, Az, USA \\ ${ }^{a)}$ Corresponding author: justinjh@email.arizona.edu
}

\begin{abstract}
We describe a CPV generator in which an off-axis paraboloidal dish reflector powers a small receiver near the focus, housing many individually illuminated multijunction cells. The receiver entrance window doubles as a field lens that forms a reduced scale image of the reflector, at concentration of $\sim 30 \mathrm{x}$. The image has a sharp boundary, and its position is stable against tracking errors. A fly's eye lens array divides the image into equal portions, and further concentrates it to $\sim 500 \mathrm{x}$ onto the cells. This approach is in contrast to nearly all previous PV and CPV, where sunlight is equal apportioned (for simple series electrical connection) directly on entering the system. In our approach, small multijunction cells are packaged into a small receiver module that will be less expensive (per watt) to manufacture than large conventional PV or CPV modules, and can be economically upgraded for 40 year lifetime. Our concept differs from REhnu's dish/receiver design [1] in its lack of obscuration and simpler cooling, using forced air convection rather than pumped liquid coolant, this made possible by the lower heat density at the cell array. In preliminary on-sun system data with a $2.4 \mathrm{~m}^{2}$ prototype powering $5.2 \mathrm{~mm}$ cells at $500 \mathrm{x}$ concentration, we demonstrate good tolerance to mispointing $\left(90 \%\right.$ at $0.5^{\circ}$ off-axis), good air cooling (cell mounting plate at $19^{\circ} \mathrm{C}$ above ambient) and uniform division of light between the cells (scatter of $3.3 \%$ rms).
\end{abstract}

\section{INTRODUCTION AND CONCEPT OVERVIEW}

Multijunction PV cells, used at high concentration, are more efficient and already less expensive in terms of $\$ /$ watt than silicon cells. For example, for cells at a 2015 cost of $\$ 35,000 / \mathrm{m}^{2}$ [2], working at $950 \mathrm{x}$ in a system with $31 \%$ overall efficiency [1], the per watt cost is $\$ 0.12$. Improved manufacturing methods, including 5x reuse of substrates [2], are projected to reduce cell cost to as low as $\$ 6,000 / \mathrm{m}^{2}$, or $\$ 0.02 /$ watt. Utility scale plants using them could be commercially very competitive, provided we can control all the other system costs - optical concentration, packaging, cooling and dual axis tracking - and extend lifetime beyond the 25 years of silicon panels.

What are our options to improve CPV LCOE? Most CPV is built around modules which are like silicon PV panels in that entering sunlight is equally divided between identical cells cooled by natural convection. The difference with PV is that the light is equally divided by identical Fresnel lenses before being focused onto the small cells, and the localized heat from the cells must be spread out by thermal conduction for natural convection. Other operational differences are that the modules need to be mounted on accurate dual axis trackers, rather than crude single axis for utility scale panels - but the area to be tracked is halved, because of the higher efficiency.

In this paper we explore a new approach to optical concentration and cell packaging and cooling, with the potential of reducing LCOE at utility scale. Our goals are to reduce the cost of the optics and the weight to be carried by the tracker, in an architecture that allows cell replacement and upgrade at low cost so that high efficiency can be maintained over a 40 year lifetime.

Our path involves using a dish reflector to collect and focus a large area of sunlight, to power many cells in a small (and upgradable) receiver at the dish focus. We differ from other CPV dish or heliostat systems in that we use imaging 
optics in the receiver to make equal division of the concentrated light between the cells, in a way that gives good tolerance to mispointing in order to help keep down tracker cost. This path has already been adopted in the dish-based system used by REhnu [1], but in a departure from this and other previous dish-based CPV, our new configuration provides air cooling of the cells, avoiding the need for heat transfer by pumped liquid. There may be little value to such thermal energy when generated in utility scale electricity plants.

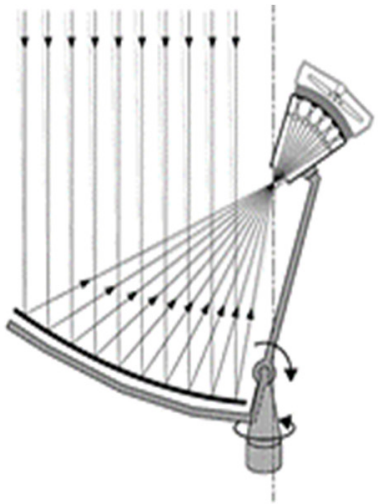

(a)

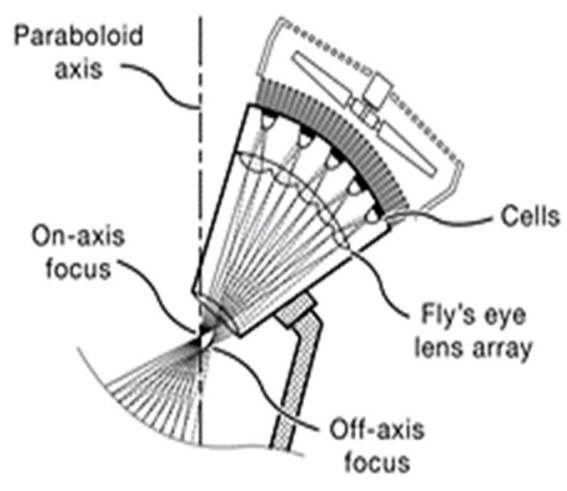

(b)

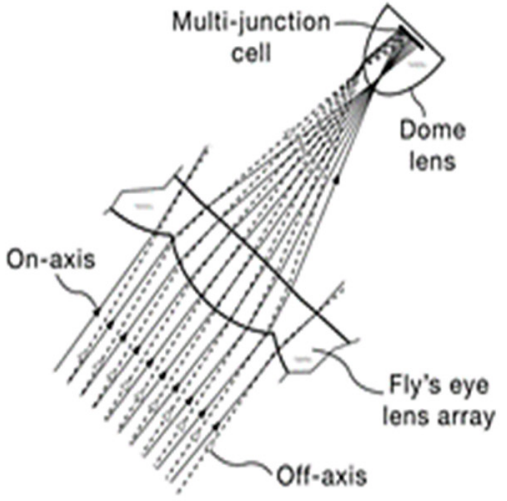

(c)

FIGURE 1. (a) Optical design showing (a) the overall system; (b) receiver components (c) detail of a single lens and cell

\section{OPTICAL DESIGN}

The overall optical design is shown in Figure 1a. An off-axis paraboloidal reflector focuses sunlight into receiver, shown in more detail in Figure 1b. Centered and off-axis rays are brought to a focus just ahead of the receiver entrance window, which is a convex meniscus lens of fused silica. This lens forms an image of the primary reflector on a fly's eye lens array - the concentration at this stage is around 30x. Each lens of the array further concentrates the light onto a cell behind, at $500-1000 x$. The cells are mounted on a concave aluminum bowl that spreads the heat out to heatsinks behind, cooled by a fan. Figure 1c shows a detail of coupling of the light from one lens into a cell. Each fly's eye lens forms an image of the sun much like that formed by a Fresnel lens (though with little chromatic aberration), and a conventional dome lens images the fly's eye lens onto the cell, to increase angular field. The advantages of this approach are:

1) The off-axis design means that there is no obscuration by the receiver.

2) At the intermediate stage of concentration - the image of the mirror formed by the field lens - all the collected light is in a sharply defined area which does not change position with tracking error. Thus the lenses in the fly's eye array across this image can be sized to accept equal amounts of sunlight, and this equal division holds even if there is some tracking error.

3) The receiver size is some 30x smaller in area (depending on the intermediate concentration) than Fresnel CPV modules of the same power. This opens the prospect of lower manufacturing cost and, importantly, low-cost upgrades during the life of a CPV plant. Replacing the receiver cell bowl with a set of upgraded cells after 20 years, with likely higher efficiency cells, will be of low cost compared to the original installed cost of the plant, whose other components, including mirrors, have 40 year lifetimes.

4) Forced air cooling (as opposed to water cooling) of the cell bowl is possible because the heat loading at $<20$ $\mathrm{kW} / \mathrm{m}^{2}$, is much less than for densely packed cells at a raw dish focus.

5) There is good potential to reduce the weight per watt carried by the dual-axis tracker, compared to regular CPV modules, and thus also to reduce the tracker cost [4]. This is important, because the dual-axis tracker is likely to cost as much as the module or receiver if CPV is to compete in LCOE at utility scale. In our approach, the primary load of ( $4 \mathrm{~mm}$ thick) glass reflectors to be carried by the trackers is $10 \mathrm{~kg} / \mathrm{m}^{2}$, or $25 \mathrm{~kg} / \mathrm{kW}$ for a future system with $40 \%$ overall efficiency. The mass of the small receivers and their support arms can likely be made as low as $15 \mathrm{~kg} / \mathrm{kW}$, for a total load of $40 \mathrm{~kg} / \mathrm{kW}$.

We envisage a utility scale implementation (Figure 2a) with individual off-axis reflectors of $10 \mathrm{~m}^{2}$ area. The overall system efficiency, assuming $45 \%$ efficient cells in a few years, is $40 \%$ (see breakdown in Table 1 below). Thus the tracker is rated at $8 \mathrm{~kW}$. A single-axis PV installation of the same power, assuming $20 \%$ efficiency, is shown to scale, 
for comparison. Figure $2 b$ shows the layout of the fly's eye lens that would be used at each focus, showing the different lens sizes needed to transmit equal light flux and power. A $21 \times 21$ lens array approximately $60 \mathrm{~cm}$ square (the size of the reference square shown) is well matched to Azur's mass produced dome lens-assemblies with $5.2 \mathrm{~mm}$ square cells. At a future $45 \%$ cell efficiency, these would yield $9 \mathrm{~W}$ each, for a $4 \mathrm{~kW}$ receiver total.

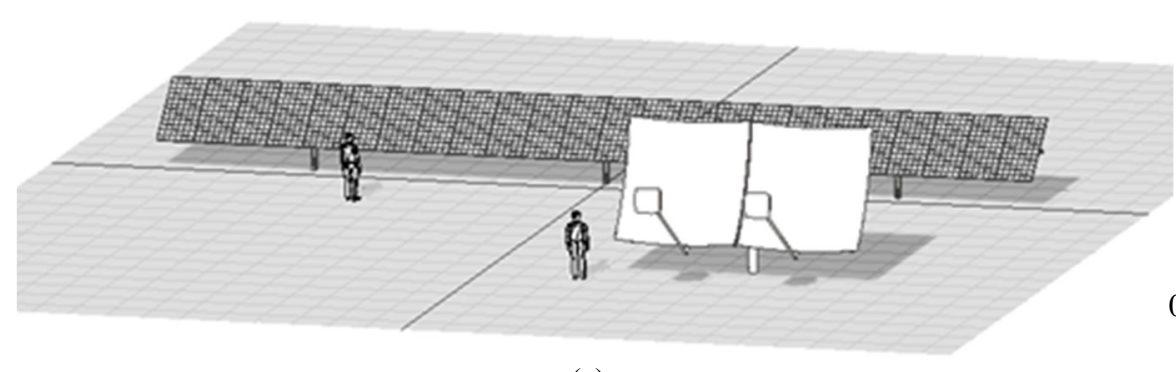

(a)

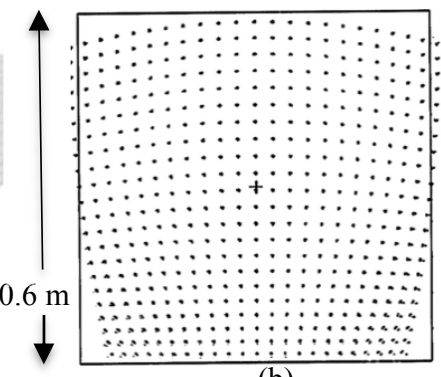

(b)

FIGURE 2. (a) An 8 kW Fly's Eye generator with a single axis tracking PV array of the same power. (b) 4 kW fly's eye array

\section{Anti-Reflection Coatings}

While the optics in our receiver design allow good control of the sunlight placement and pointing tolerance, the reflected light must pass through three lenses: field lens, array and dome. To maintain high throughput, surface reflections and absorption must be minimized across the broad spectral band of multijunction cells. To this end, we have developed graded index antireflection coatings of two types, for silica (field lens) and for borosilicate glass (fly's eye and dome lenses).

For the field lens, which is made of fused silica because of its negligible absorption and very low thermal expansion, we have developed a sol-gel based coating applied via a spin-coating technique. Two layers of different

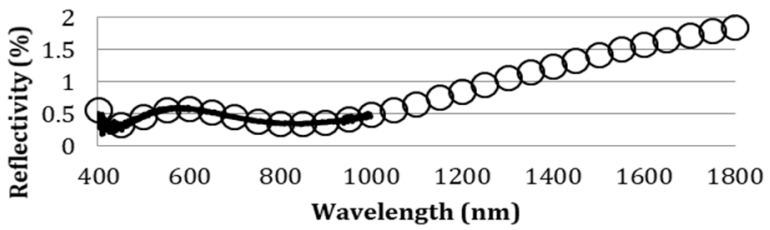

(a)

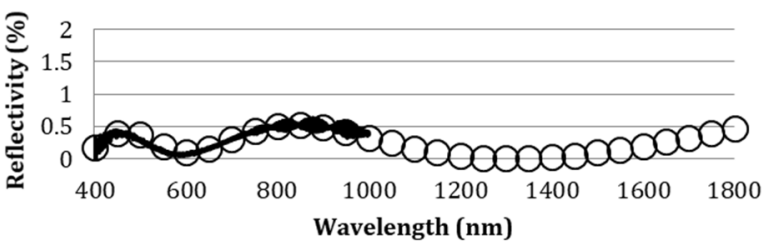

(b)

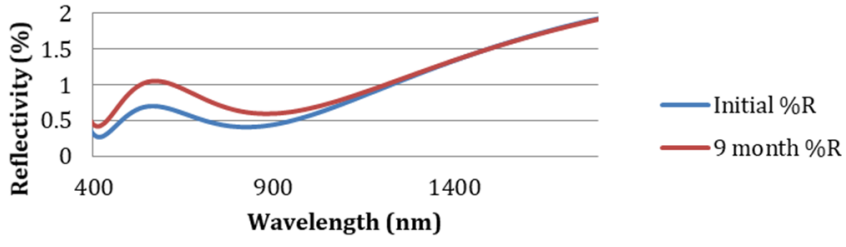

(c)

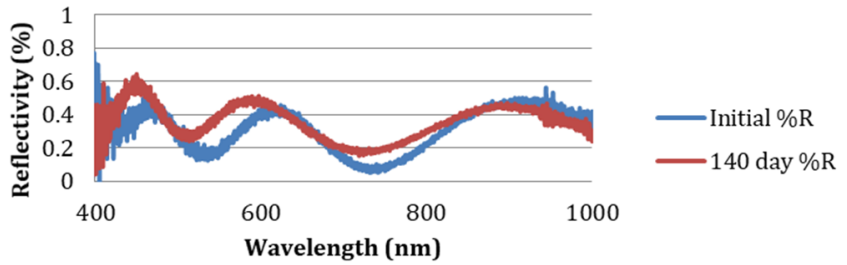

(d)

FIGURE 3. Single surface reflectivities (a) 2-layer sol-gel on fused silica and (b) chemically leached borosilicate glass

(c) Change in surface reflectivity of a 2-layer sol-gel AR coating after 9 months of concentrated on-sun exposure;

(d) a chemically leached anti-reflection coating before and after 140 days of exposure in a particle-filtered chamber 
porosity and refractive index are deposited successively. This reduces Fresnel reflections to $0.5 \%$ per surface from 400-1000 nm, and to an average of 1\% per surface from 1000-1800 nm, as shown in Figure 3 (a).

The fly's eye and dome lenses are press-molded aspheres of borosilicate glass, a process used extensively to make lenses for LED lamps. For these we use a chemical leaching process [5]. This process involves first heat treating the borosilicate glass to induce phase separation. The glass in then immersed in a leaching solution which preferentially removes one of the phases. The result is a film of graded nanoscale porosity, and thus graded refractive index that reduces Fresnel reflections to $0.5 \%$ per surface over a wavelength range of $400-1800 \mathrm{~nm}$. See Figure 3(b).

The field lens will be exposed directly to ambient atmosphere and dust particulates and must therefore be durable in an outdoor environment. Figure 3(c) shows reflectivity of a lens with this coating type after 9 months of on-sun testing compared to its initial reflectivity. The coating reflectivity increased by an average of $0.25 \%$ over the 400 $1000 \mathrm{~nm}$ range, and only $0.10 \%$ over the $1000-1800 \mathrm{~nm}$ range. The fly's eye and dome lenses are contained within the receiver, thus they will not be exposed to particulate matter, but they will experience moisture cycling. A coated optic was placed in a particle filtered chamber and left outside for a total of 140 days. The test was conducted during the southwestern US monsoon season. Figure 3(d) shows a plot of the reflectivity of the optic before and after the test. Aside from a slight shifting of the interference pattern, no significant increase in reflectivity was measured.

(a)

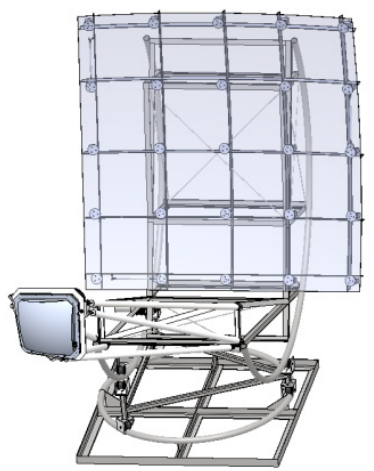

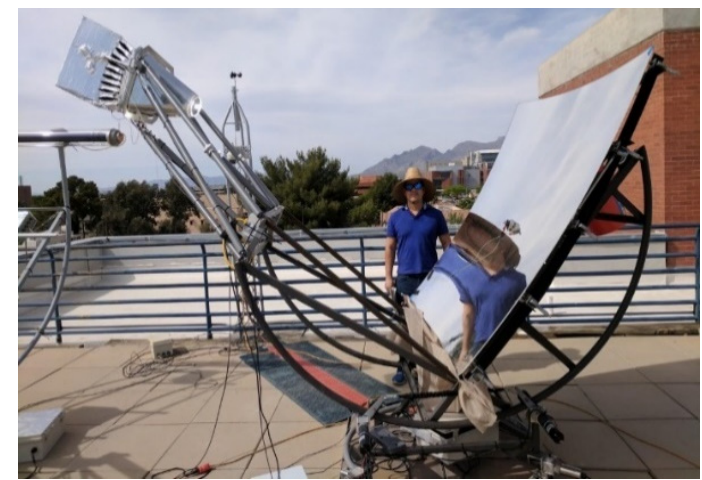

(b)

FIGURE 4. The prototype system (a) as seen by the sun. (b) as built, under test

\section{PROTOTYPE AND INITIAL RESULTS}

To prove the concept, a prototype has been largely completed, and on sun system tests were started on April 5, 2018, in time to get some preliminary results for the CPV-14 meeting. The prototype uses an off-axis paraboloidal primary reflector, left over from a previous project. It has a square aperture of area $2.41 \mathrm{~m}^{2}$, and $2 \mathrm{~m}$ focal length, the parent vertex just outside one corner of the mirror. It makes use also of a "rocking chair" rooftop dual axis tracker made for a previous project [3]. The overall layout of the prototype with the off-axis receiver is shown is the design drawing of Figure $4 \mathrm{a}$, in a view as seen from the sun, and in Figure $4 \mathrm{~b}$ as implemented on the roof of Steward Observatory, in on-sun testing. The mirror support structure is extended out to the off-axis focus with a hexapod, used for fine adjustment of the orientation and position of the receiver.

The receiver design concept is as described above and shown schematically in Figure 1, with a field lens, fly's eye lens array, cells with dome lenses, an aluminum bowl support with heat sinks, and cooling fans. The design parameters and manufacturing details for the prototype receiver are as follows:

\section{Receiver Elements and Manufacture}

Field lens: A meniscus lens of fused quartz with $100 \mathrm{~mm}$ diameter and $400 \mathrm{~mm}$ focal length. It forms a concave and trapezoidal image of the primary mirror, $300 \times 300 \mathrm{~mm}$, where the fly's eye lens array is located. At the time of the initial tests, the lens surfaces had not been anti-reflection coated by the process described above.

Fly's eye lens array: The array has 144 approximately square lenses in a 12 by 12 array. The lenses are sized for equal division of the incoming sunlight, so that each cell receives light from a $128 \mathrm{~mm}$ x $128 \mathrm{~mm}$ square $\left(0.0163 \mathrm{~m}^{2}\right.$ of incoming sunlight. The overall array shape is a concave sphere with radius of curvature of $400 \mathrm{~mm}$, chosen so that each lens is normal to incoming rays. The lens sizes, chosen so each one receives equal power, vary in size and area 
from $20 \mathrm{~mm}$ square $\left(410 \mathrm{~mm}^{2}\right)$ to $25 \mathrm{~mm}$ square $\left(630 \mathrm{~mm}^{2}\right)$. The smallest lenses are at the corner of the array furthest from the axis of the parent system, where the intensity of the pupil image is highest.

In future high-volume manufacture, the lens arrays may be made at low cost by press molding in one piece from a sheet of glass. But for this prototype the array was assembled from individual aspheric lenses cut to shape and glued together. We used individually press-molded plano-convex lenses of borosilicate glass, manufactured all to the same $40 \mathrm{~mm}$ diameter and shape. After the lenses were heated to cause phase separation, they were individually bonded by hot glue to an axisymmetric supporting hub. Then cutting into the individual 4-sided shapes was accomplished by a numerically controlled water jet. The sides of the lenses are nearly square, but were cut with slight (and different) draft angles to ensure that the array would fit together with the overall $400 \mathrm{~mm}$ radius and with minimal gaps. The lenses were then assembled on a jig, supported by their hubs, and glued together by wicking in optical cement. The assembled and glued array is shown in Figure 5a. Note that apart from the edge lenses, which were not cut around the perimeter, the lenses lower right (the anti-vertex corner) are smaller than those upper left. An anti-reflection coating was applied to the phase separated lenses using the leaching process described above.

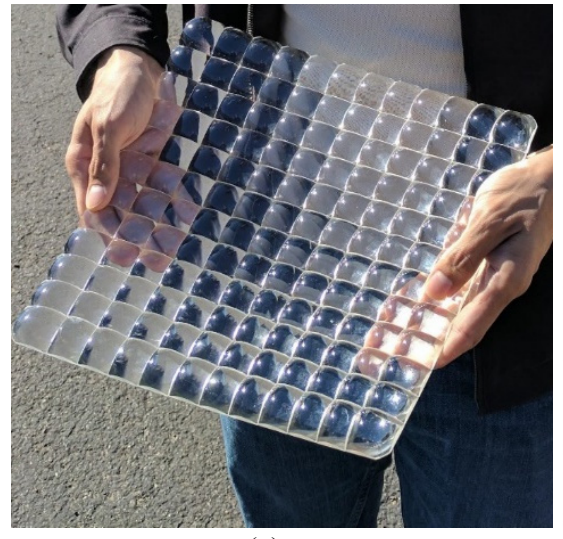

(a)

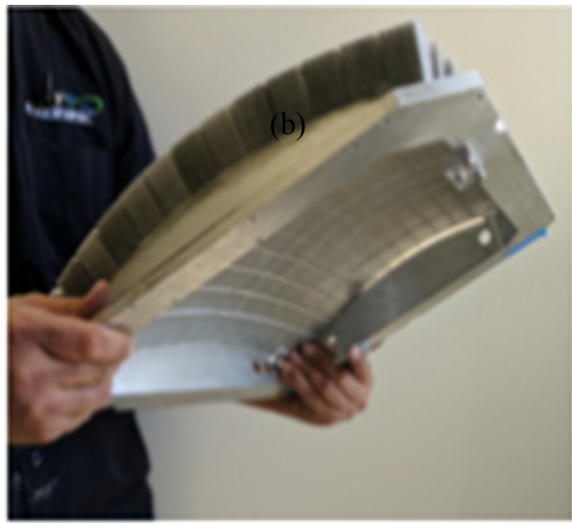

(b)

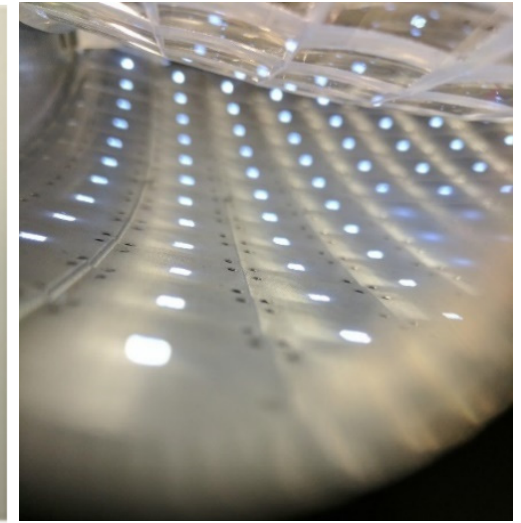

(a)

FIGURE 5 (a) The assembled and glued array. (b) The cell-mounting bowl. (c) The array in lab test with test lamp.

Cell assemblies with dome lenses: For these initial tests, we used cell assemblies 3C44A supplied by Azur Space, with $5.2 \mathrm{~mm}$ square cells mounted on alumina substrates. To these we attached press molded aspheric dome lenses of borosilicate glass, antireflection coated by the leaching process described above, and also an aluminum mounting piece below, for attachment with thermal grease to the bowl support.

Actively cooled bowl support: Figure $5 \mathrm{~b}$ shows the cell mounting bowl, prior to cell installation. The heatsinks behind are attached in rows using thermal epoxy. The rows have $1 \mathrm{~cm}$ gaps between them. An air manifold formed from bent aluminum sheets is used so that air from a BLDC fans is forced to flow through the fins, escaping near the dome and passing out along the $1 \mathrm{~cm}$ gaps. The air escapes through the radial, lozenge-shaped openings visible in the receiver in Figure 5b. Figure 5c shows an alignment lab test with the fly's eye lens array (top) in place above the bowl and a point source near the field lens to simulate the primary solar image. The array forms an array of focused spots on the dome plate, where the cell assemblies were mounted.

\section{Preliminary Performance Measurements}

Initial performance tests have been made in the lab and on-sun. Lab tests of cooling performance by heating the dome plate to $80^{\circ} \mathrm{C}$, and then measuring the cooling rate with the fans turned on. Knowing the thermal mass of the bowl, we obtained a cooling constant of $0.0158 \mathrm{C} / \mathrm{W}$, for a fan input power of 13.2 watts.

For initial characterization of performance on sun, we populated the bowl with a sparse array of 10 cell assemblies, connected in series with voltage sensors across each cell to monitor individual cell performance. A thin layer of soot was deposited on the rest of the bowl, to test on-sun cooling performance. We measured a rise in bowl temperature of $19^{\circ} \mathrm{C}$ under $980 \mathrm{DNI}$ illumination, when $1.7 \mathrm{~kW}$ was being absorbed by the black bowl, representing very good cooling. 
The alignment of the ten sample cells relative to the image formed by the fly's eye lenslet above was measured by taking individual IV curves while the tracker performed a 5-by-5 raster scan, moving in $0.25^{\circ}$ steps in azimuth and elevation. We find alignment errors of $0.25^{\circ} \mathrm{rms}$ (corresponding to $0.8 \mathrm{~mm} \mathrm{rms} \mathrm{offset).} \mathrm{Figure} \mathrm{6a} \mathrm{shows} \mathrm{the} \mathrm{IV} \mathrm{curve}$ for each cell at its optimal pointing. The maximum power averages $4.41 \mathrm{~W}$, with rms scatter of $0.15 \mathrm{~W}$, or $3.3 \%$ of the mean. We note also that open circuit voltages range over 0.12 volts, corresponding to a temperature spread of $30^{\circ} \mathrm{C}$. This arises because of known imperfections in cell attachment.

Figure $6 \mathrm{~b}$ shows the power received by each cell as a function of the area of the array lens powering it. We find no systematic error, thus in general the array lenses are correctly sized for equal power, though with $3.3 \% \mathrm{rms}$ scatter as noted above. From the raster scan data, we have also determined the sensitivity to off-axis pointing error. This is shown in Figure $6 \mathrm{c}$. The power at $0.5^{\circ}$ offset is reduced to $90 \%$, and to $80 \%$ for $0.7^{\circ}$. This is very comparable to the pointing tolerance achieved by good Fresnel-based CPV modules, and is broad for dish-based CPV systems.

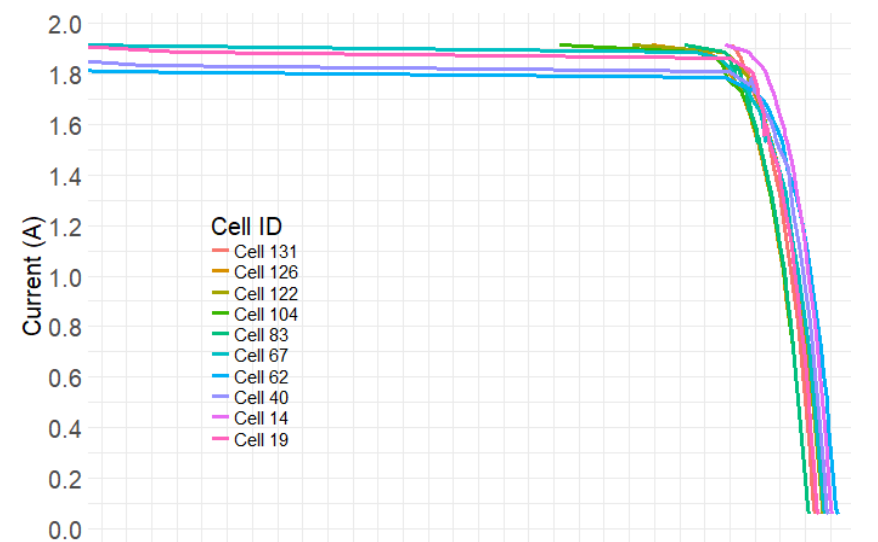

(a)

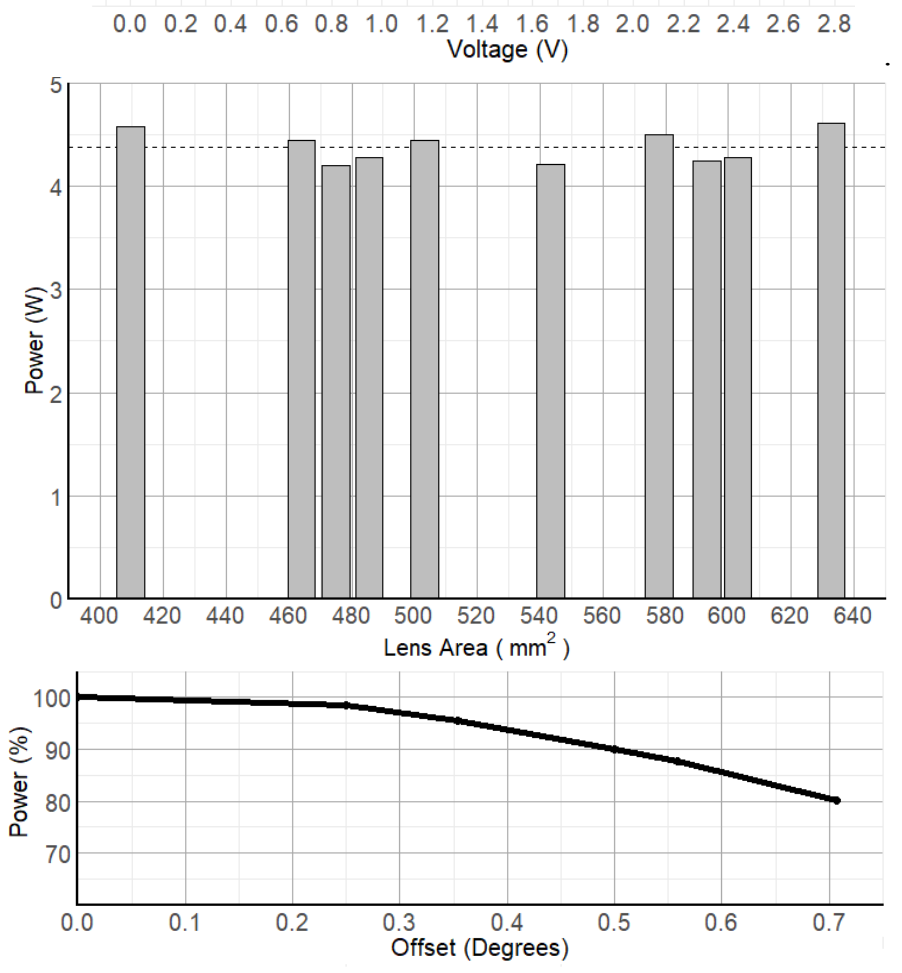

(b)

(c)

FIGURE 6. (a) IV curve for each cell at its optimal pointing; (b) The maximum power measured by each cell as a function of lens area; (c) Power vs pointing offset. 


\section{Efficiency}

The measured average cell power of $4.41 \mathrm{~W}$ was obtained at an (actual) DNI flux of $1000 \mathrm{~W} / \mathrm{m}^{2}$, corresponding to a solar input to the primary mirror of $16.3 \mathrm{~W} /$ cell, and thus a raw efficiency of $27.1 \%$. Corrected to CSTC $\left(25^{\circ} \mathrm{C}\right.$ cell temperature) this rises to $29.0 \%$, corresponding to only modest optical and electrical throughput of $69 \%$. There are however a number of known areas of loss in this initial and uncompleted system, to be corrected as we improve the prototype. Table 1 lists the various optical, thermal and electrical balancing factors that relate cell efficiency to overall system efficiency for both the target and measured prototype systems. The future target with $45 \%$ cells is $89 \%$ throughput for $40 \%$ overall CSTC system efficiency. For the present prototype the main known additional losses come from the field lens $(6 \%$, no anti-reflection coating), the dome and fly's eye lenses $(4.5 \%$ form iron impurity in the borosilicate glass and imperfect AR coating), and 10\% from cell power loss and mismatch from residual optical errors. We are now working to reduce these losses. With these improvements, CPV using this dish-fly's eye architecture with system efficiency of $40 \%$ and a 40 year lifetime, from cell upgrades, should be highly competitive and have lower LCOE than conventional PV, in sunny parts of the world.

TABLE 1. CSTC efficiency: future target for $45 \%$ cells, and current prototype results with $42 \%$ cells

\begin{tabular}{|l|r|r|l|}
\hline Source & \multicolumn{1}{|c|}{ target } & \multicolumn{1}{c|}{ measured } & Reason for difference \\
\hline Nominal cell efficiency & $\mathbf{4 5 \%}$ & $\mathbf{4 2 \%}$ & \\
\hline Mirror loss & 0.94 & 0.92 & Dirty prototype mirror \\
\hline Field lens loss & 0.99 & 0.93 & No AR coating yet of prototype field lens \\
\hline $\begin{array}{l}\text { Leached lens reflection } \\
\text { loss }\end{array}$ & 0.99 & 0.98 & Incomplete coating fly's eye lenses \\
\hline Glass absorption & 1 & 0.97 & $144 \mathrm{ppm}$ iron content vs 20 ppm target \\
\hline Lens scattering loss & 1 & 0.985 & AR coating microstructure coarseness \\
\hline Lens surface damage & 1 & 0.985 & Ammonium bifluoride damage \\
\hline Gaps between lenses & 0.99 & 0.97 & 350 m gaps between prototype lenses \\
\hline Cell power mismatch & 0.98 & 0.95 & Differential Pmax in cell outputs \\
\hline Optical alignment & 0.99 & 0.96 & Residual optical misalignment, cell spillover \\
\hline Other & 0.99 & 0.98 & \\
\hline CSTC system efficiency & $\mathbf{3 9 . 4 \%}$ & $\mathbf{2 8 . 7 \%}$ & \\
\hline
\end{tabular}

\section{REFERENCES}

1. N. Didato et al, Dish Based CPV: Performance and Reliability Improvements Based on Field Experience. (Proc. CPV-14, AIP, 2018)

2. K. Horowitz, M. Woodhouse, H. Lee and G. Smestad, A bottom-up cost analysis of a high concentration PV module (AIP Conference Proceedings, 2015) p 1679.

3. C. Davila-Peralta, Hyatt, J., Alfred, D., Struble, M., Sodari, F., \& Angel, R., Dish-based CPV-T for rooftop generation. (Proc. CPV-13 AIP, 2017) p 1881.

4. R. Angel, B. Cuerden, and A. Whiteside, Lightweight dual-axis tracker designs for dish-based HCPV, (Proc. CPV-10, 2014).

5. H.L. McCollister, R.B Pettit. J. Antireflection Pyrex Envelopes for Parabolic Solar Collectors, Sol. Energy Eng 105 (4), 425-429, 1983 